\title{
The Effectiveness of Some Balance Exercises in Improving the Skillful Level of the Forward Dive Tuck among Divers
}

\author{
Hussein A. Abdel-Salam*, Mostafa M. Nour**, Yosry M. Hassan***
}

\section{Introduction and Research Problem}

$\mathrm{D}$ iving is one of the sport activities characterized with spectacular artistic performance and great difficulty. It requires a multitude of different physical qualities that enable the diver to perform the different skills required by the sport $(7: 1)$.

The main factor governing he skillful performance of the diver is achieving two main tasks: a limited travel away that frees the diver from the board, and a rotation movement determined by the selected diving group.

The performance and mastering of the dive depend on the diver's possessing a high level of physical abilities the most important of which is balance, both static and dynamic. A diver always needs balance during the different stages of the dive, including preparation, approaching and mounting the board, flight and entry to water. (16: 100).

Several specialists in the sports field agree that balance is a physical characteristic which determines the physical fitness necessary for performing different activities. Thus, it may be considered a major component in the majority of sport activities that require standing or moving on a narrow space, such as gymnastics or diving. (1:450), (2: 20), (10:149).

*Assistant Professor, Aquatic Sports Training Department, The Faculty of Physical Education, Abu Qir, Alexandria University, Egypt.

**Assistant Professor, Exercises and Gymnastics Training Department, The Faculty of Physical Education, Abu Qir, Alexandria University, Egypt.

***Lecturer, Exercises and Gymnastics Training Department, The Faculty of Physical Education, Abu Qir, Alexandria University, Egypt.
While the balance of an athlete depends on his ability to control his nervous and muscular systems, in a manner that enables him to maintain a position that protects him against losing balance,

the effectiveness of body balance increases with the increase in the sensitivity of the sensory sensors, that are responsible for balance. (17:2).

The skill of the forward dive tuck from the springboard is included in the basic group of forward dives performed around the horizontal axis of the body which were decided by the international diving federation.

Hobie (1995) suggests that the importance of this skill can be summarized as one of the basic skills of high level junior divers that require a low degree of difficulty (1.2). Mastering the technical performance of dives of higher degrees of difficulty in the same group, however, depends on that same skill. This has led diving specialists to consider it a very important skill in diving exercises (18:115).

Ewald (1985) suggests that when a player has enough motor balance, he will need to exert less effort to perform the dive with a high skillful level. If motor balance does not directly affect the successful skillful performance of the dive, the lack of this physical quality will indirectly lead to unskilled and weak performance.

Modern training methods that are based on physiological sciences promote the training of learning the different senses, since the relationship between sensory (vestibular / visual / bodily) sensors and controlling the individual balance, especially in air, is very important. This applies to the selected skill because the 
vestibular, visual and bodily signals play a vital role in detecting vibrations, and providing the nervous system with different information about the directions and speed of these vibrations. The integration between these sensory sources and the nervous system increases the ability of the body to maintain and control balance (17:2).

The individual's ability to control his balance is dependent on the supportive relationship between his/her sensory systems whose essential system consists of:

- sensory information coming from the inner ear or vestibular system;

- sensory information coming from the visual system;

- Deep and shallow senses coming from the specialized sensory units existing in skin, the muscles, the tendons, and the joints. Proper; Oceptive (13:260) $(12: 105)$.

The present study examines the training of vestibular system, as a system which has a relationship with the forward dive tuck, especially after the player leaves the diving board and moves in air. The vestibular system is then physiologically responsible for keeping balance and directing the body in air in the right direction relating to gravity. The study is also an attempt towards standardizing a physical exercises programme to improve that system. This is reflected in improving the player's balance in air and on entry to water, and in turn leads to a successful performance of the skill and encourages the diver to perform the rest of the highly difficult dive groups efficiently.

Researchers attribute their dealing with the current study to the recommendations of the researchers who dealt with the problems of the diving sport bio-mechanically and morphorolgically. They suggest standardizing the physical programmes to improve the physical factors related to diving, especially the balance factor necessary for the diver during the three stages of diving (preparation, approaching and mounting and flight).
A review of the number of dives recorded by in the international rules of diving showed that the dives with rotation represent $53.25 \%$. These are dives with a nature of their own and differ from other dives in that they require a twisting movement during rotation. The vestibular fluid of the middle ear plays a vital role in controlling the body in space and in directing it in a correct way to ensure the diver's vertical approach towards water, and facing the water with head and body in a straight position.

Thus, the current study is important because it aims at training the vestibular system that improves balance, which in turn leads to improving the skillful level of performing the forward dive tuck.

\section{Study Objectives :}

Standardizing a training programme of physical exercises to improve the job efficiency of the vestibular system of divers.

Improving the skillful performance level of the forward dive tuck.

\section{Study Hypotheses}

Practicing the suggested training programme leads to improving the job status of the vestibular system which in turn leads to improving balance.

Practicing the training programme improves the skillful performance level of the forward dive tuck.

\section{Study Procedures}

Methodology : The experimental method was used, being suitable for this type of study.

Geographical Scope: The study was conducted in Alexandria Sporting Club.

Study Sample: The research sample was selected in an intentional manner and included 12 divers from the Alexandria Sporting Club. The sample was randomly divided into two equal groups, a control group of 6 divers who did not apply the suggested training programme, and an experimental group of 6 divers who applied the programme. 
Table 1

The mean, standard deviation and torsion coefficient of the research sample.

$N=12$

\begin{tabular}{|c|c|c|c|c|}
\hline $\begin{array}{c}\text { Statistical } \\
\text { Significance } \\
\text { Variables }\end{array}$ & $\begin{array}{c}\text { Mean } \\
\mathrm{M}\end{array}$ & $\begin{array}{c}\text { Standard } \\
\text { Deviation } \\
\text { SD }\end{array}$ & Median & $\begin{array}{c}\text { Torsion } \\
\text { Coefficient }\end{array}$ \\
\hline Height $(\mathrm{cm})$ & 171.4. & $r .0 . v$ & $179 .$. & $\because 184_{-}$ \\
\hline Age (years) & $1 V . \Sigma V$ & $1 . \wedge \Sigma 1$ & $1 Y .07$ & $\cdot \leqslant v \cdot-$ \\
\hline Weight (kgm) & $70.1 \% 0$ & 5.0 .09 & 70.1 & $.19 r_{-}$ \\
\hline
\end{tabular}

Table1 shows that the torsion coefficient did not approach \pm 3 . This indicates the consistency of the sample in the primary variables examined.

\section{Physiological and Physical Tests}

During the survey study conducted by the researchers on the literature on physiological and physical tests field, and meetings held with experts, a group of physiological and physical tests were selected. The said tests were approved by $90 \%$ or more of the experts using a questionnaire form. The following tests were selected:

\section{- Physical Tests:}

1. armstand test
2. headstand test.

3. standing on a divided box, jumping, landing on feet, and standing still. (Attachment 3).

- Physiological Tests: (Attachment 2)

1. Electro-physical test of sensory analyzers.

2. test of compound balance.

3. balance strategy.

4. test of skill performance evaluation. (Attachment 4).

Table 2

Comparison between the control and experimental groups in the research variables before conducting the experiment.

$N 1+N 2=12$

\begin{tabular}{|c|c|c|c|c|c|}
\hline \multirow{2}{*}{$\begin{array}{c}\text { Statistical Significance } \\
\text { Variables }\end{array}$} & \multicolumn{2}{|c|}{ Control group } & \multicolumn{2}{|c|}{ Experimental group } & \multirow{2}{*}{ T test } \\
\hline & M & SD & M & $\mathrm{SD}$ & \\
\hline Armstand & 1.77 &.$\leqslant \varepsilon$ & 1.11 &.$T^{2}$ & 1.77 \\
\hline Headstand & 10.4 & r.01 & 10.19 & r.07 & $1 . \leqslant \varepsilon$ \\
\hline Jump-on-box examination & T & $\cdot \wedge \cdot 1$ & $r . \leqslant q$. &.$\vee \wedge 0$ & $1 . r$ \\
\hline Vestibular test & $01 . Y_{0}$ &.$\times 91$ & 09.1 & .1199 & $.0 \leqslant r$ \\
\hline Compound balance test & $77 . V$ & 0.07 & 71.9. & 7.1 & $\cdot .7 \%$ \\
\hline Balance strategy & VY.VI & $\leqslant .10$ & $V Y . \wedge$. & $\sum . r T$ & 1.1 \\
\hline $\begin{array}{c}\text { Skillful performance } \\
\text { evaluation }\end{array}$ & $r .00$ & $\because \vee 7$ & r.o. & $. V \leqslant 0$ & $.09 \leqslant$ \\
\hline
\end{tabular}

Tabular value of $(\mathrm{T})$ at 0.5 level $=\mathbf{2 . 2 2}$

Table 2 and Figure 1 show no statistical significant differences between the experimental group and the control one in all of the research variables. The calculated $(T)$ value is lower than the tabular $(T)$ value at the 0.5 level.

This indicates the equivalence of the two research sample groups. 


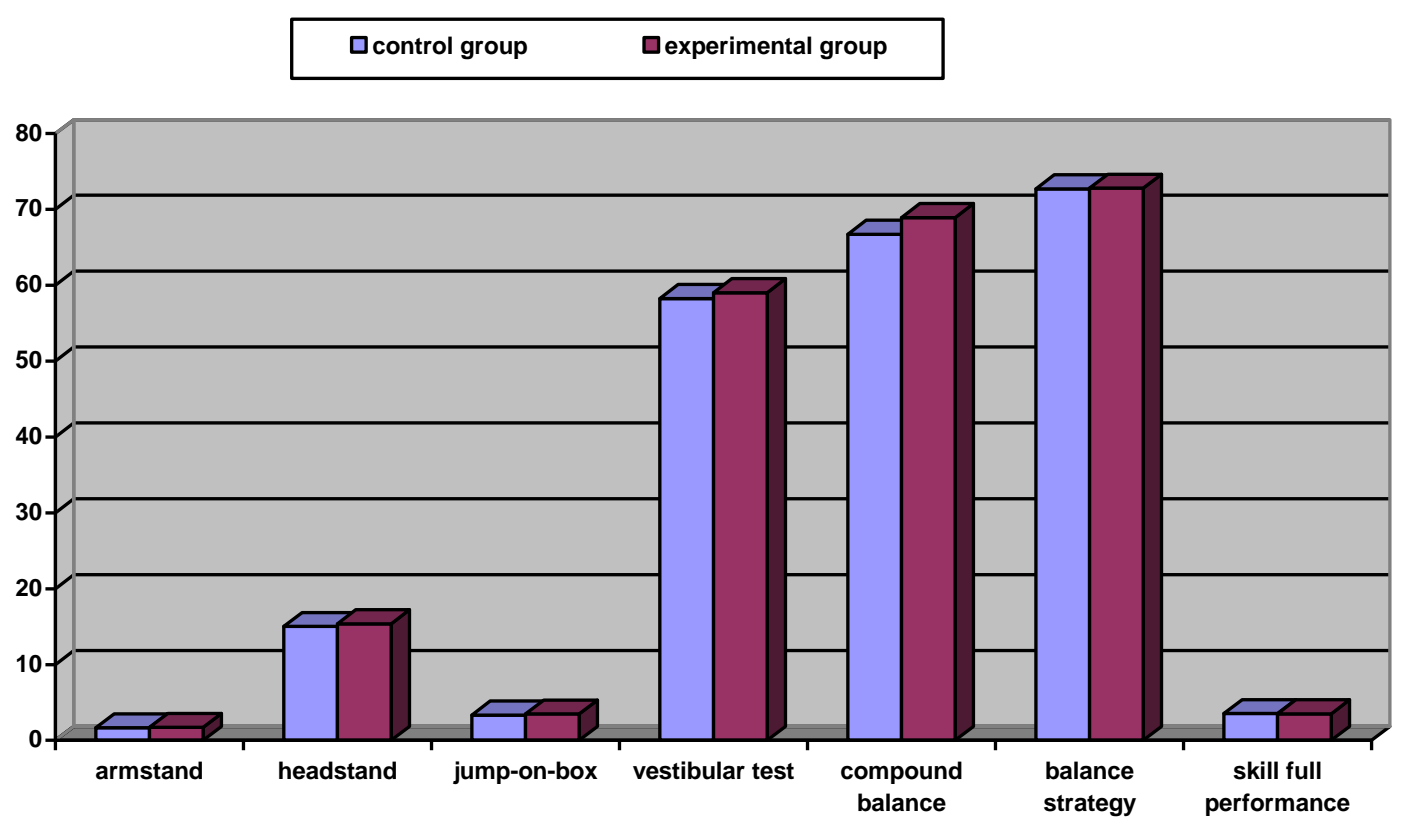

Figure 1

Figure 1 shows the comparison between the control group and the experimental group in the research variables before conducting the experiment.

\section{Measurement equipment and tools}

- pulse programming equipment.

- balance measuring equipment (Attachment 2)

- video camera.

- medical scales for measuring weight.

- Rastameter for measuring height in cms.

- stop watch to the nearest $0.01 \mathrm{sec}$.

- divided box.

- matresses

- computer.

\section{Skillful performance tests}

The forward dive tuck skill was videoed and referred to experts to evaluate the final stage of the skill, in the light of the skillful performance evaluation form. (Attachment 4).

\section{Pre-measurements}

The pre-measurements were conducted on the research sample (the control and the experimental groups) before conducting the experiment. Data was individually taken on each player.

\section{Programme Implementation}

The experimental group applied the training programme according to the low intensity intervalal training method. The basic exercises of the programme were selected in the light of similar studies, and the pilot study conducted, to select the programme exercises which included 22 exercises divided into three parts.

\section{First: warm-up exercises}

The time allowed for warm-up exercises was 10 minutes before each training unit divided into 6 stations, each having only one exercise, bringing the total number of exercises in the warm-up stage to 6 inter-related exercises. The limbs and the trunk were involved in the exercises, and the speed of performance was taken into consideration. The player started with a one-minute run. The exercises were distributed over the pre-set stations and would take 9 minutes, so that the duration of performing each exercise was 30 seconds, with 
a shifting time of 15 seconds between each exercise and the following one.

\section{Second: the basic part}

The duration of the basic exercise doze was set at 45 minutes divided into 10 stations, each containing one exercise, bringing the total number of exercises in the programme to 10 . (Attachment 1).

Standardizing the exercise intensity in the training circuit of the basic part

Based on the pulse rates indicating the intensity of the different training loads which were individually set according to the targeted pulse rates of each diver, derived from the following equation:

Maximum pulse rate $=220-$ age

The average of performance pulse rate for the required period $=$

Rest pulse rate $+($ maximum pulse rate - rest pulse Required Intensity

100

Intensity exercises were standardized according to the maximum style. Rest pulse rate was measured during rest and the pulse rate was calculated at the required intensity.

1. The pulse programming equipment used was standardized to a pulse rate equal to the required intensity which was $50 \%$ of the targeted pulse rate, expressed, for example, as 141 pulse/min., i.e., which is the targeted training pulse rate.
2. Intensity exercises were performed on a nonstop basis until the equipment whistle was heard to declare reaching the required training pulse rate $=141$ pulse $/$ min.

3. Exercises were stopped, while running in place for 1-2 minutes to maintain the same intensity level reached, and achieve the physiological adaptation of the body systems to the targeted intensity.

4. The number of sessions was calculated (a session $=$ the 10 exercises $), \quad 3$ sessions $\times 10$ exercises $=30$ exercises, total $=30$ exercises.

Through this, the training doze for the first and second weeks was identified, being one group = 3 sessions made up of 30 exercises which is equal 141 pulse / min., which is the targeted training period for the first and second weeks.

\section{Third: the final part}

This included 6 stations, each consisting of one exercise, bringing the total number of exercises in this stage to 6 exercises of relaxation which played an important role in getting rid of the load thrown on the diver physically and psychologically.

\section{Post-measurements}

The post-measurements of the study sample (control and experimental groups) were conducted after the experiment, under the same conditions of pre-measurements. These were compared for the purposes of statistical treatment. 
Results

Table 3

A comparison between pre-measurements and post-measurements in research variables for the experimental group.

\begin{tabular}{|c|c|c|c|c|c|c|c|}
\hline \multirow{2}{*}{$\begin{array}{c}\text { Statistical Significance } \\
\text { Variables }\end{array}$} & \multicolumn{2}{|c|}{ Pre-measurement } & \multicolumn{2}{|c|}{ Post-measurement } & \multirow{2}{*}{$\begin{array}{c}\text { Difference } \\
\text { between } \\
\text { means }\end{array}$} & \multirow{2}{*}{$\begin{array}{c}\text { Calculated } \\
\qquad(\mathrm{T}) \\
\text { value }\end{array}$} & \multirow{2}{*}{$\begin{array}{l}\text { Improvement } \\
\text { percentage }\end{array}$} \\
\hline & M & SD & M & SD & & & \\
\hline Armstand & $1 . \times 1$ & •rt & $\varepsilon .9$. & .01 & $r .19$ & Ir. $\varepsilon r *$ & $\% \wedge \uparrow .0$ \\
\hline Headstand & 10.19 & r.07 & rV.r. & $\varepsilon .+1$ & 17.91 & T.r. & $\% 1 \cdot 9 . \wedge$ \\
\hline jumping-on-box test & $r . \leqslant q$ & $\cdot \vee \wedge$ & ^. $\cdot 1$ & 1.10 & $\varepsilon .0 Y$ & 10.11 & $\% 1 r 9.0$ \\
\hline Electrophysiological test & $09 . \cdot 1$ & r.11 & $v \cdot .1$ & r. $\leqslant 1$ & 11.99 & ^.7. & $\% \wedge \wedge . \vee 9$ \\
\hline Compound balance test & 71.9. & $\varepsilon . r \mu$ & $\vee \wedge . \varepsilon$ & 0.10 & 9.0 & $1 \cdot .19$ & $\%$ \%.৩А \\
\hline balance strategy & VY.A. & $\varepsilon . r$ & 11.0. & $\varepsilon . \wedge \wedge$ & ^. $\vee$ & V. $\varepsilon$. & $\% 11.90$ \\
\hline Skill performance evaluation & r.o. & $\because v \leq 0$ & 7.00 & 1.19 & $r .0$ & $9 . . * *$ & $\% 9 \wedge$ \\
\hline
\end{tabular}

Tabular $(T)$ value at $0.05=2.78$

Tabular $(\mathrm{T})$ value at $0.01=4.60$

Table 3 and graph 2 show differences of statistical significance at the $(0.5)$ level where the calculated (T) value is higher than the tabular $(T)$ value which varied between $(6.30 *)$ and $(12.43 *)$. There was an improvement in all research variables favoring post-measurements.

pre-measurement $\square$ post-measurement

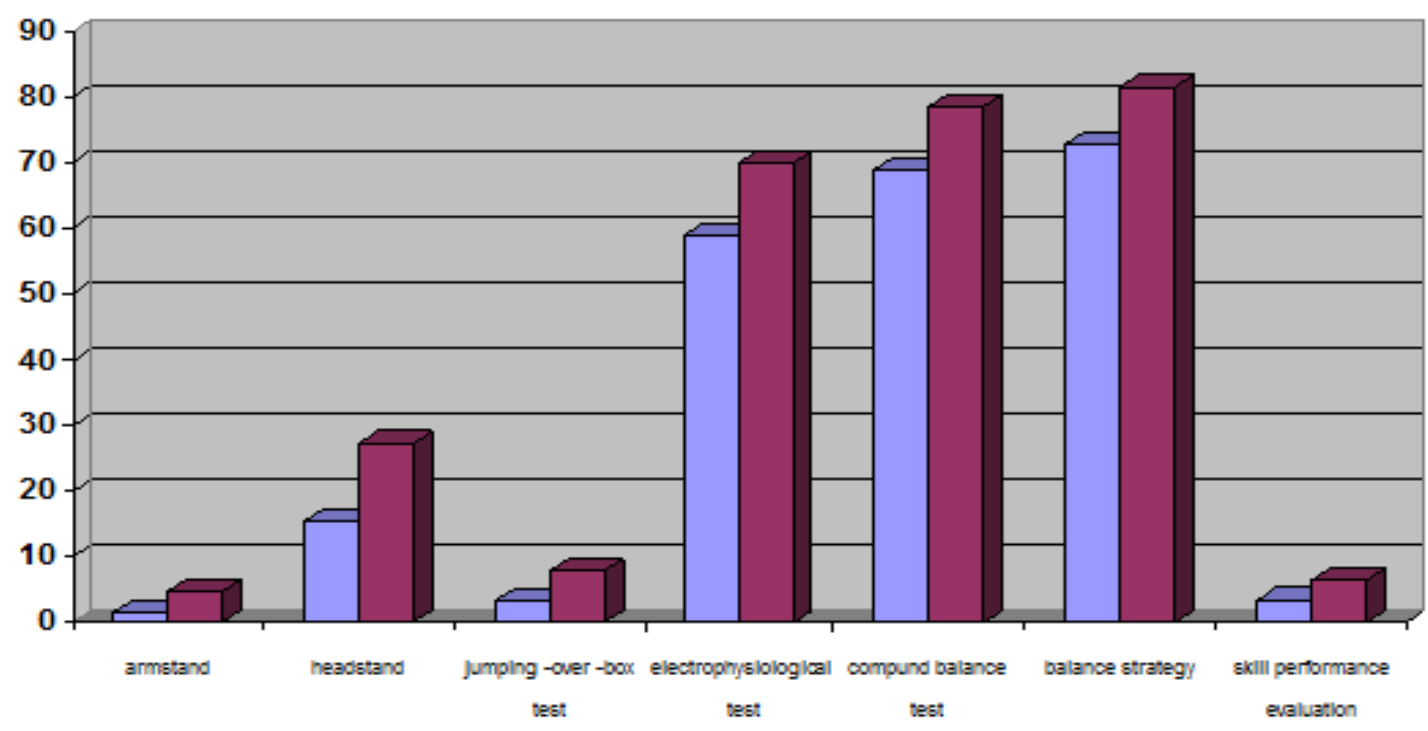

Figure 2

Comparing pre-measurements and the post-measurements in research variables of the experimental group. 
Table 4

Comparing pre-measurements and post-measurements in research variables of the control group

\begin{tabular}{|c|c|c|c|c|c|c|c|}
\hline \multirow{2}{*}{$\begin{array}{c}\text { Statistical Significance } \\
\text { Variables }\end{array}$} & \multicolumn{2}{|c|}{ Pre-measurement } & \multicolumn{2}{|c|}{ Post-measurement } & \multirow{2}{*}{$\begin{array}{c}\text { Difference } \\
\text { between } \\
\text { means }\end{array}$} & \multirow{2}{*}{$\begin{array}{l}\text { Calculated } \\
\text { (T) value }\end{array}$} & \multirow{2}{*}{$\begin{array}{l}\text { Improve } \\
\text { ment } \\
\text { percentage }\end{array}$} \\
\hline & M & $\mathrm{SD}$ & M & SD & & & \\
\hline Armstand & 1.77 & $\because \leqslant \varepsilon$ & $r .0$ & $.7 V$ & و & r.人 & $r$ r. $\leqslant q$ \\
\hline Headstand & 10.4 & r.01 & 17.14 & r.VA & 1.1 & r.9. & V.r \\
\hline Jumping-on-box test & سب.r & $\cdot \wedge \cdot 1$ & r.q। & .91 & .01 & $\varepsilon . r$ & $\mid V . \leqslant 1$ \\
\hline Electrophysiological test & OA.Yo & $\cdot(Y 9)$ & $7 \cdot Y \cdot$ & • & 1.90 & r.79 & ع \\
\hline Compound balance test & $77 . V$ & 0.07 & 79.0 & 0.09 & $r . \wedge$ & $\varepsilon .9 \%$ & $\leqslant .19$ \\
\hline balance strategy & VY.VI & $\leqslant .10$ & $v \varepsilon .1$ & $\varepsilon .00$ & $1 . r$ & $.9 \leq r$ & $1 . \vee \wedge$ \\
\hline skill performance evaluation & $r .00$ & $\because \vee 7$ & $\leqslant .0$ & $. \wedge \leq$ & .90 & Q r. & rY.VT \\
\hline
\end{tabular}

Tabular $(\mathrm{T})$ value at $0.05=\mathbf{2 . 7 8}$

Tabular $(\mathrm{T})$ value at $0.01=4.60$

Table 4 and graph 3 show that there are differences of statistical significance at the $(0.05)$ level, but it is equal to the change rates in the experimental group who applied the suggested training programme, since the calculated

(T) value as higher than the tabular (T) value, but at a level lower than the experimental group which varied between 0.942 and 3.81 .

It was also obvious that there no improvement occurred in some of the research variables in the postmeasurements of the control group.

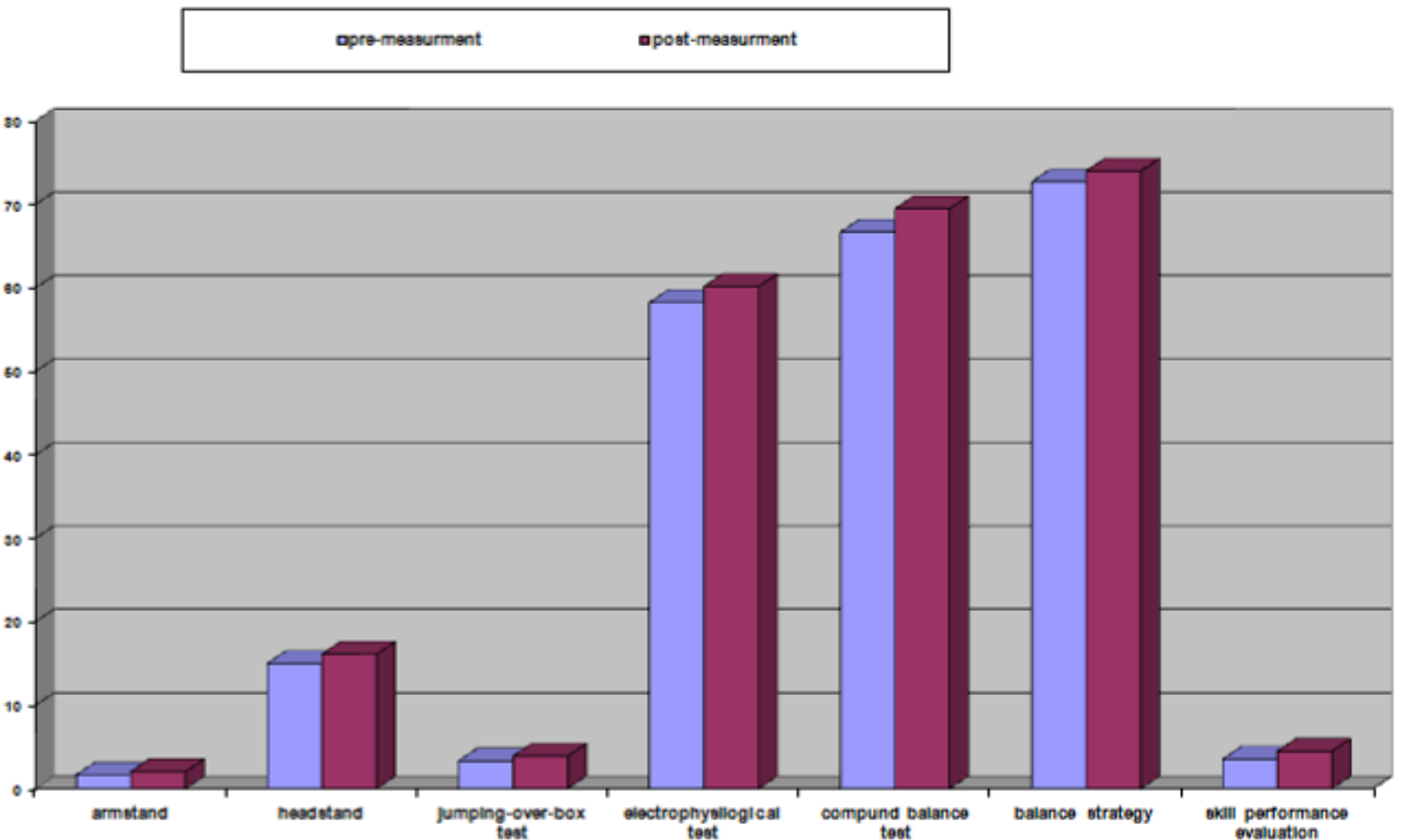

Figure 3 
Table 5

Comparing the experimental and control groups in post-measurements in research variables

\begin{tabular}{|c|c|c|c|c|c|c|}
\hline \multirow{2}{*}{$\begin{array}{c}\text { Statistical Significance } \\
\text { Variables }\end{array}$} & \multicolumn{2}{|c|}{ Pre-measurement } & \multicolumn{2}{|c|}{ Post-measurement } & \multirow{2}{*}{$\begin{array}{c}\text { Difference } \\
\text { between means }\end{array}$} & \multirow{2}{*}{$\begin{array}{l}\text { Calculated }(\mathrm{T}) \\
\text { value }\end{array}$} \\
\hline & M & SD & M & SD & & \\
\hline Armstand & $\varepsilon .9$. & .01 & $r .0$ & $.7 V$ & r.^o & $\varepsilon .1 T$ \\
\hline Headstand & rV.r. & $\varepsilon .+1$ & 17.14 & r.VA & 11.11 & $T . M T$ \\
\hline jumping-on-box test & $\wedge . \cdot 1$ & 1.10 & r.q) & $\cdot .91$ & $\varepsilon .1$ & $v .10$ \\
\hline Electrophysiological test & $v \cdot .1$ & r. & $T \cdot . r \cdot$ & •r. & 9.9 & 0.7 \\
\hline Compound balance test & $\vee \wedge . \varepsilon$ & 0.10 & 79.0 & 0.09 & $\wedge .9$ & ऍ.^. \\
\hline Balance strategy & 11.0 & $\varepsilon . \wedge \wedge$ & $v \leq .1$ & $£ .00$ & $v . \leqslant 9$ & $\varepsilon .11$ \\
\hline skill performance evaluation & 7.00 & 1.19 & $\varepsilon .0$ & $\because \wedge \varepsilon$ & $r .0$ & r.qr \\
\hline
\end{tabular}

Tabular $(\mathrm{T})$ value at $0.05=\mathbf{2 . 2 2}$

Tabular $(\mathrm{T})$ value at $0.01=3.17$

Table 5 and graph 4 show differences of statistical significance at the $(0.05)$ level in all of the research variables favoring the experimental group.

\begin{tabular}{|ll|}
\hline aexperimental group & acontrol group \\
\hline
\end{tabular}

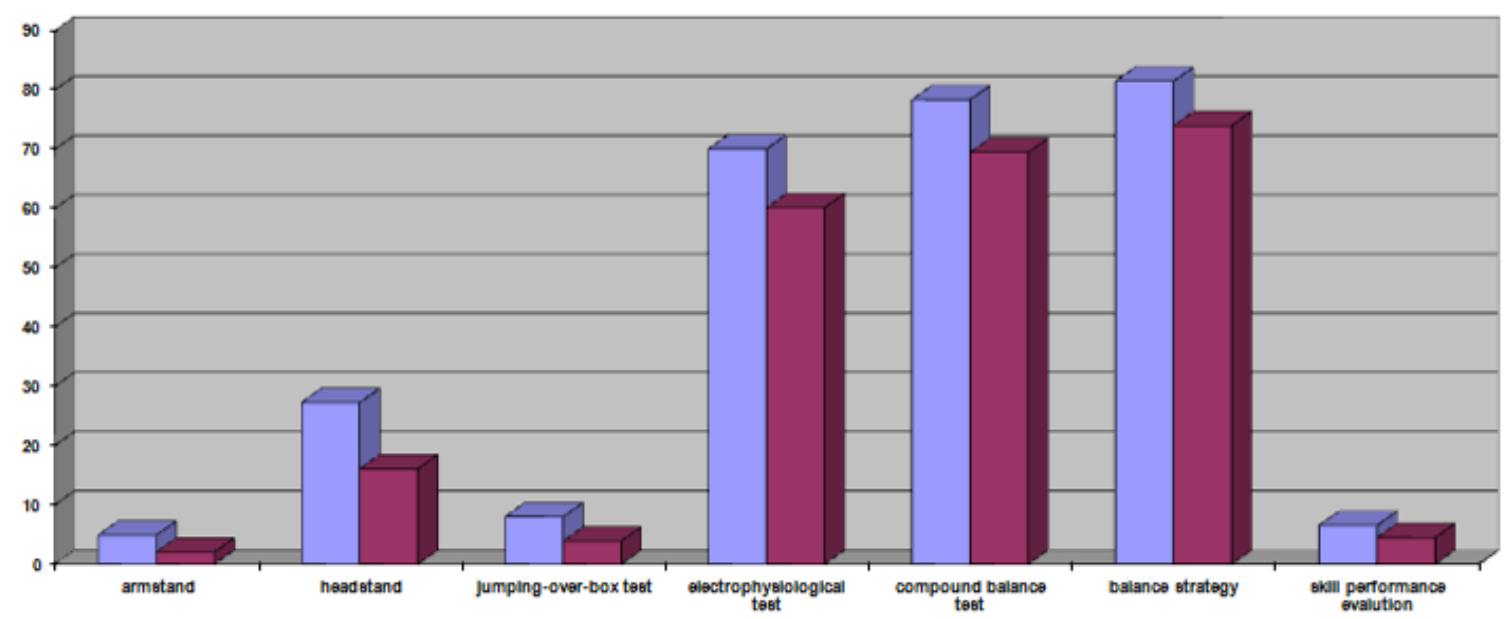

Figure 4

Comparing the experimental and control groups in the research variables of post-measurements. 
Table 6

Improvement in research variables in the experimental and control groups expressed as a percentage N 1+ N 2 = 12

\begin{tabular}{|c|c|c|}
\hline $\begin{array}{c}\text { Statistical Significance } \\
\text { Variables }\end{array}$ & Percentage for the experimental group & Percentage for the control group \\
\hline Armstand & $1 \wedge 7.0$ & $r r . \leqslant q$ \\
\hline Headstand & $1 \cdot 9.1$ & V.ru \\
\hline jumping-on-box test & 149.0 & $\mid V . \Sigma 1$ \\
\hline Electrophysiological test & $11 . \vee 9$ & $r . r \varepsilon$ \\
\hline Compound balance test & IT.VA & $\varepsilon .19$ \\
\hline Balance strategy & 11.90 & $1 . \vee \wedge$ \\
\hline skill performance evaluation & $9 \wedge$ & Y૫.Vฯ \\
\hline
\end{tabular}

Table 6 and graph 5 show that the percentage of the improvement was in favor of the experimental group, varying between 11.95 and 186.5 , whereas the control group had a percentage of 1.78 - 26.7.

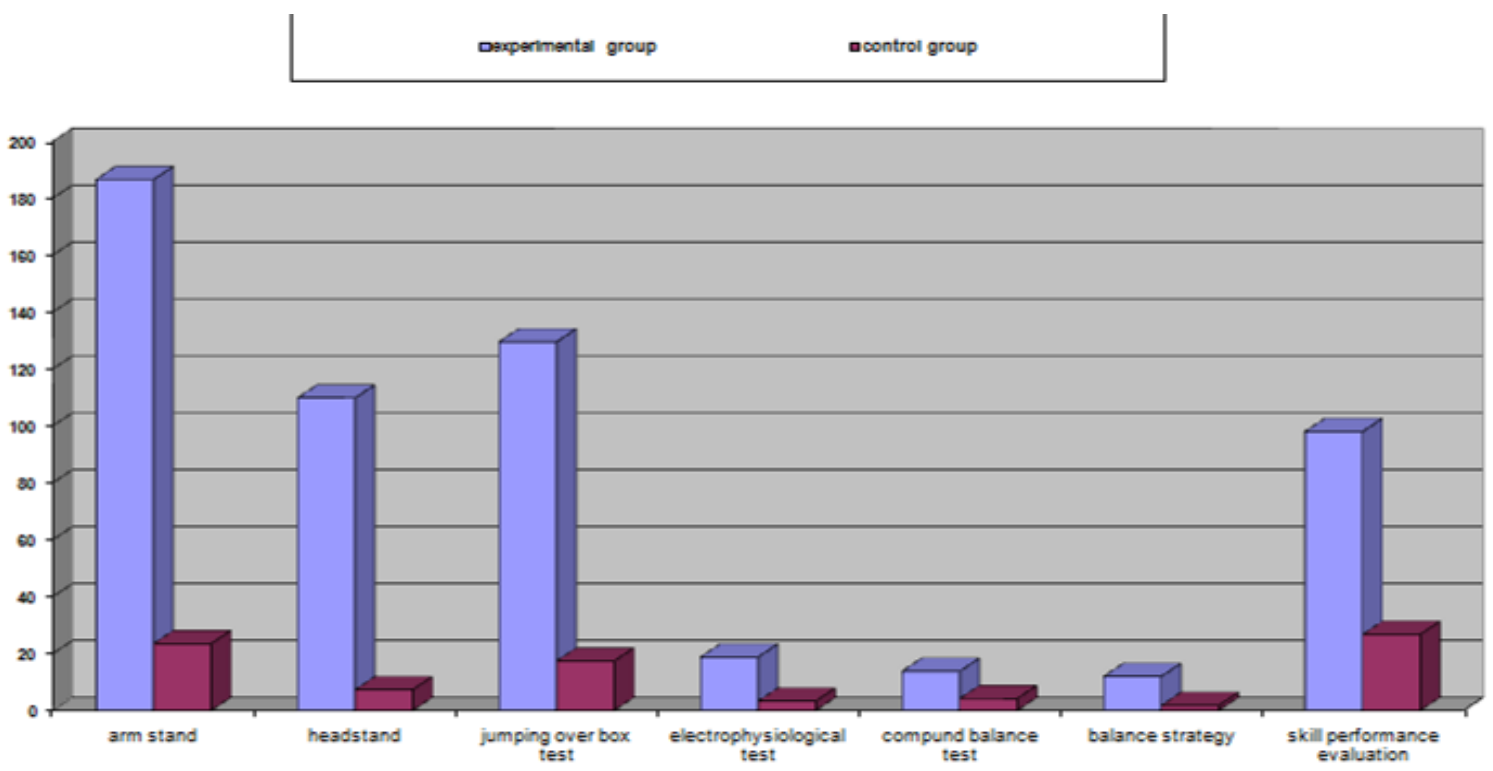

Figure 5

Improvement in research variables in the experimental and control groups expressed as a percentage

\section{Discussion of the results}

\section{First : discussing the results of balance tests}

Tables 3 and 5 and graphs 2 and 4 show that there are statistically significant differences between pre-measurements and postmeasurements and between the control group and experimental group in the tests of static and dynamic balance favoring post-measurements in the experimental group. The authors attribute this to the application by the experimental group of the suggested training programme which included specific exercises for balance. The practice led to improvements of balance in general, and improvement of the job efficiency of the vestibular system in particular, which in turn improved the balance element. The programme included exercises of a rotating nature which stimulate the lymphatic fluid in the inner ear. This resulted in adaptation of the balance keeping system, reduction of sensitivity 
of the inner ear, thus creating a relative stability of the body, both during standing still or moving. Continuous training using balance exercises has an effect on developing the neural coordination and training the balance keeping systems in the semicircular canals of the middle ear, which, is reflected in turn on the skill performance level. This explains the improvement of the skill performance level of the experimental group compared to that of the control group.

Table 6 and figure 5 show higher improvement rates achieved by the experimental group compared to the control group who did not apply the training programme of balance exercises. Balance is thus directly proportional to the efficiency of vestibular system. The more efficient the vestibular system is, the higher the balance performance rates. This comes in accordance with the findings of studies by Marigan (19: 37), Laila El-Shahat (14: 37) and Zakiya Omran (8:35) which suggest that loss of balance and feeling dizzy occur as a result of the intensity of stimulation applied to the vestibular system by the balance keeping system in the inner ear.

\section{Second: discussing the results concerning the vestibular system}

Tables 3, 4 and 5 show statistically significant differences in the vestibular sensors between pre-measurements and post-measurements, and between the control group and the experimental group, favoring post-measurements of the experimental group. This is attributed to the effect of the training programme which included exercises of high speed rotating movements. Such movements stimulated the vestibular system and consequently led to a real improvement in the job efficiency of the system and exceeding the system threshold, especially because the exercises are performed in different positions and directions. Rotation and changes of direction characterizing the exercises included in the training programme help the vestibular sensors achieve detection and orientation of the body's position in space and improve the process of providing the central nervous system with information about acceleration and deceleration and the angular declination and body deviation. Consequently, an increase in the efficiency of the vestibular system is reflected in keeping the body in an upright position through controlling the harmony of skeletal muscles.

Table 6 again shows higher improvement rates achieved by the experimental group compared to the control group. The regular and continuous application of the training programme by the experimental group resulted in a great improvement in the vestibular sensor. This finding is in conformity with results reached by Iglal Mohammed Ibrahim (2: 10), Hanaa Abd El-Wahab (15: 225), Peter Johnson (20: 301) and Ahmed El-Shazly (5: 65), indicating that the continuous training loads involving repetition and continuity of performance lead to the adaptation of the lymphatic fluid in the semicircular canals in the inner ear. Thus, there is a relative stability of balance during the performance of sudden movements of rotation and somersaults.

\section{Third: discussing the results of implementing the skill performance}

Tables 3, 4, and 5 show statistically significant differences in the degree of evaluating the skill performance between pre-measurements and post-measurements and between the control group and the experimental group favoring postmeasurements of the experimental group. The authors attribute this to the application by the experimental group of the suggested training programme which included specific exercises with regular training loads that improved the efficiency level of the vestibular system, which in turn effectively improved the skillful level of the forward dive tuck. This is confirmed by the improvement rates shown in table 6, favoring the experimental group. Practicing the balance exercises led to an improvement in the job efficiency of the vestibular system. This, in turn, contributed to maintaining body equilibrium. Rotation of the head, as a result of the effort exerted, causes a flow of the lymphatic fluid in the semicircular canals, utricle and saccule. The movement of this fluid stimulates the neural receptors and the person perceives the new 
position of the head in relation to the body which directly responds to the stimulants in a way that allows the body to keep its balance in the new position. Consequently, a player's perception of the motor skill in the different stages improves and this improves performance too. This is consistent with results confirmed by Zakiya Omran (8:2), Ihsan Ali Sharaf (3:31) and X. Radvay (21:36) i.e., the practice of different physical exercises improves the job efficiency of the sensory receptors as reflected in improving the skillful performance.

\section{Conclusions}

In the light of the study objectives, the hypotheses set by authors of this paper, the selected sample and the statistical treatment employed, the following conclusions were reached:

- The regular practice of the suggested training programme by divers leads to improving the job efficiency of the vestibular system, thus leading to improvement in balance, which is reflected in turn in improving the skillful level of the forward dive tuck.

Balance (static and dynamic) and the improvement in the status of the vestibular system are directly proportional.

- Job efficiency of the vestibular system and the skillful level of performing the forward dive tuck are directly proportional

\section{Recommendations}

Within the framework of the study sample, the procedures followed, the statistical treatment employed and the results attained, the researchers make the following recommendations:

- The divers should practice the suggested training programme for its effect on improving balance which is reflected in improving the skillful level of the forward dive tuck.

- Consideration should be given to integrating exercises for the sensory systems, especially the vestibular system, in the divers' preparatory programmes in the different sports organizations.
- Further studies should be conducted on sports activities involving sensory systems as basic factors affecting the skillful performance level.

\section{References}

\section{References in Arabic}

1- Abul Ula Ahmed Abdel Fattah \& Mohamed Sobhy Hassanein, Sport Physiology and Morphology and Measurement and Evaluation Methods, First Edition, Dar Al Fikr Al-Araby, 1997

2- Iglal Mohamed Ibrahim, the effect of a Training Programme on the inner ear as Related to Dynamic Balance, 1997

3- Ihsan Aly Sharaf \& Kamal Mera, Anatomy, a General Study of the Structure of the Human Body, Muassaset Al - Thakafa Al- Gamieya, third edition, 1980

4- Ahmed Fuad Al-Shazly, Rules of Balance in Sport, Dar A-Maaref, Cairo, 1995

5- Ahmed Fuad Al-Shazly, Principles of Bio-mechanic Analysis in Sport, Zatul Salasel, Kuwait, 2006

6- $\quad$ Ahmed Mohamed Khater \& Aly Fahmy Al-Beik, Measurement in Sport, Dar AMaaref, Cairo, 1984

7- Omayma Ibrahim Al-Agamy \& Azza Abdul Ghany Abdul Aziz, An Analytical Study of Some Kinematic Parameteres of Forward Dive Tucks as Related to Dynamic Balance of Divers, Nazareyat wa Tatbiqat, Faculty of Physical Education for Men, Alexandria, issue 32, 1999

8- Hussein Ramadan Mohamed Darwish, Quantitative Change in Mounting Variables between Springboard as Related to the Level of Difficulty of Some Group of Twist Dives, unpublished Ph. D. Dissertation, Faculty of Physical Education for Men, Helwan University, 1990

9- Zakeya Gaber Ahmed Mohamed Omran, A Suggested Programme to Improve Motor Balance as Related to Job Efficiency of Vestibuln Alyser and Indicators of at Rest and Positional Physiological Tremors, unpublished Ph. D. Dissertation, Faculty of Physical Education for Girls, Alexandria, 2000 
10- Talha Hussein Hussam Eddin, Kinetic and Job Principles of Sport Training, Dar alFikr Al-Araby, Cairo, 1994

11- Adel Mohamed Zein Eddin, the Effect of the Streghth of Pushing with Legs on the Performance Level of Some Platform Dives among Junior Divers, Nazareyat Wa Tatbiqat, Faculty of Physical Education for Men, Alexandria, 1990

12- Aly Mohamed Mutawie \& Ahmed Khater, Skill, Monograph 14, the Motor Learning Series, Dar A-Maaref, 1994

13- Enayat Mohamed Farag \& Fatma Ibrahim, Rhytmic Exercises, Rhytmic Gymnastics and Sport Shows, Dar al-Fikr AlAraby, First Edition, 1994

14- Layla Al-Shahat, The Effect of Developing Balance on the Skillful Performance Level of Balance Beam among Female Gymnastics Juniors, Faculty of Physical Education for Girls, Alexandria, 1996

15- Hanaa Abdel Wahab Hassan, Improving Motor Balance and its Effect on the Job Efficiency of the Vestibular System, Performance Level of Disc Throwing Events as Related to Emotional Balance, Journal of Faculty of Physical Education for Girls, Alexandria, No. 15, July 1998

16- Wafiqa Mostafa Salem, Aquatic Sports, Aims, Teaching Methods and Evaluation
Approaches, Monshaat Al Maaref, First Edition, 1997

17- Yosry Mohamed Hassan, The Effect of Sensory Analysers on the Performance Level of Some Rotations and Somrsaults, unpublished $\mathrm{Ph}$. D. Dissertation, Faculty of Physical Education for Men, Alexandria, 2007

\section{References in English}

18- Dvvlin CD, Sands WA at all: Peripheral Vision and back Tuck Somersaults. Department of Sport Studies, Xavier university, Cincinnati, oH, 2001.

19- DHHap information and Technical,: How the balance system Works, WB Sounders, Co 2004.

20- Hobie Billingsley: Diving Illustrated, The Ronald Press Company, New York, 1995.

21- Madigan R, Grey Rd: Cognitive strategies of university athletes, Dept of psychology, University of Alaska.

22- Peter Janssen, MD: Lactate threshold training copyright @ 2001.

23- X. Radvay. C. Dauxerre: Contribution of balance training in AMD Patients rehabilitation. Article international congress series, volume 1282, Sept, 2005, page 271-274. 
